\title{
Comment
}

\section{Pesquisa científica: conceitos básicos}

Ginete Cavalcante Nunes ${ }^{\prime}$;MariaCristina Delmondes do Nascimento ${ }^{2}$; Maria Aparecida Carvalho Alencar Luz ${ }^{3}$

Resumo: Em ciências, torna-se imprescindível que se encontre evidências que possam confirmar as hipóteses levantadas por uma situação de investigação. O presente estudo visa refletir a pesquisa científica, discutndo as proposições de alguns autores de acordo com os seus respectivos objetivos.

Palavras-Chave: Ciências. Pesquisa. Conceito de pesquisa

\section{Scientific research: basic concepts}

\begin{abstract}
In science, it is essential to find evidence that can confirm the hypotheses raised by a research situation. This study aims toreflect the scientific research, discussing the propositions of some authors according with their respective goals.
\end{abstract}

Keywords: Sciences. Search. Research concept

\section{Introdução}

No presente estudo, far-se-á uma reflexão sobre o conceito de pesquisa e seus tipos, bem como sua importância. Será apresentado inicialmente o conceito de pesquisa científica, numa perspectiva mais abrangente, e em seguida, apresentar-se-á discussão mais particular sobre pesquisa descritiva.

$\mathrm{O}$ que nos $\mathrm{m}$ a essa reflexão é um conjunto de experiências no âmbito da docência e na formação de professores. A partir dessas experiências, foi possível inferir, um complexo cenário de demandas de naturezas diversas, quando referimo-nos à pesquisa científica. Dessa forma nos indagamos: quais os conceitos de pesquisa científica e como se dá a diferenciaçãoção entre eles?.

\section{Refletindo Sobre a Pesquisa Científica}

Segundo Gil (2010, p.17), a pesquisa científica é "o procedimento racional e sistemático que tem como objetivo proporcionar respostas aos problemas que são propostos".

\footnotetext{
${ }^{1}$ Cursa o Mestrado Profissional em Letras (PROFLETRAS) na Universidade Federal Rural de Pernambuco (UFRPE). E-mail: ginetecavalcante@bol.com.br;

${ }^{2}$ Cursa o Mestrado em Educação pela Universidade Hispano Guarani (HIG) E-mail: cristina_delmondes@hotmail.com

${ }^{3}$ Cursa o Mestrado em Educação pela Universidade Hispano Guarani (HIG) E-mail: macluz27@ gmail.com
} 
Cervo e Bervian (1996) conceituam a pesquisa como uma atividade que busca solucionar problemas diversos utilizando-se dos processos científicos. A pesquisa parte, pois de uma dúvida ou problema e, com o uso do método científico, busca uma resposta ou solução.

Já Marconi e Lakatos (2007, p. 157) trazem uma reflexão quanto à importância de direcionar a pesquisa científica para o conhecimento da realidade. "A pesquisa, portanto, é um procedimento formal, com método de pensamento reflexivo, que requer um tratamento científico e se constitui no caminho para conhecer a realidade ou para descobrir verdades parciais". As mesmas autoras, em obra anterior, esclarecem que o método científico se caracteriza por ser falível, pois não há verdades absolutas ou definitivas. O que a ciência faz é pesquisar hipóteses que possam ser testadas e verificadas por procedimentos sistemáticos, por pesquisadores da área em questão. As hipóteses podem ser confirmadas ou refutadas durante o processo de pesquisa, mas ambas podem favorecer o desenvolvimento científico levando à formulação de novas hipóteses e à busca de novas respostas. (LAKATOS; MARCONI, 1991).

No mesmo sentido, Ruiz (2008, p.48) afirma que a pesquisa científica se trata da "realização concreta de uma investigação planejada, desenvolvida e redigida de acordo com as normas da metodologia consagradas pela ciência. É o método de abordagem de um problema em estudo que caracteriza o aspecto científico de uma pesquisa".

Sendo a metodologia a busca de esclarescimentos para os questionamentos que emergem do íntimo do pesquisador, notemos o que diz Tonozi-Reis (2005) quando expõe que a pesquisa científica é uma ação intencional que tem como objetivo ampliar o nosso conhecimento sobre a realidade. É um processo de investigação detalhada e organizada para interpretarmos o mundo natural, social, histórico ou cultural. Dessa forma a pesquisa tem sido compreendida como um processo de produção de conhecimento para interpretação da vida, dos homens e das coisas, isto é, conhecimentos que nos auxiliem a compreender e a dar sentidos à realidade vivida.

Segundo LAVILLE \& DIONNE (1999), pesquisador é aqui um descritor, um narrador dos fatos que o mesmo percebe nunca um interventor, ele observa, vigia, não interage, mesmo que ele já tenha uma perspectiva preconcebida do objeto de estudo.

Seria inadequado perguntar se o pesquisador que estuda a lei da gravidade universal gosta ou não dos corpos que se atraem. Por outro lado, e difícil imaginar que, sobre a questão da evasão escolar - retomando esse exemplo —, o pesquisador não tenha qualquer concepção previa. De fato, e provável que estime, ao menos, que a evasão escolar não e algo bom. Seus valores lhe dizem. E é com esse preconceito que aborda seu objeto e sobre ele fará o estudo. (LAVILLE \& DIONNE, 1999, p. 34).

Entendemos que mesmo que o pesquisador tenha uma perspectiva preconcebida do objeto de investigação ele deve ter uma sensibilidade para colocar-se no lugar do outro,buscando entender 
melhor o que diz, sente, percebe, pois, os investigados não são apenas clientes ou objetos, mas pessoas que pensam e sentem, para que dessa forma se crie um clima de confiança, favorecendo que os dados coletados ao longo do processo sejam significativos. Apresenta-se também como fundamental a competência para realizar corretamente a expressão escrita registrando o que se observou, viu, ouviu e coletou na investigação.

\section{Pesquisa Descritiva}

A pesquisa descritiva inclui um estudo observacional, onde se compara dois grupos similares, sendo assim, o processo descritivo visa à identificação, registro e análise das características, fatores ou variáveis que se relacionam com o fenômeno ou processo. A grande contribuição da pesquisa descritiva é proporcionar novas visões sobre uma realidade já conhecida.

De acordo com Aidil Barros e Neide Aparecida (1990) na pesquisa descritiva ocorre:

[...] descrição do objeto por meio da observação e do levantamento de dados ou ainda pela pesquisa bibliográfica e documental.Das pesquisas descritivas pode-se chegar à elaboração de perfis,cenários etc. A ênfase metodológica pode ser mais quantitativa do que a qualitativa.Busca percentuais,médias,indicadores,curvas de normalidade etc (AIDIL e NEIDE, 1990, p. 34)

Segundo os autores Herivelto Moreira e Luiz Gonzaga Callefe em seu livro Metodologia da pesquisa para o professor pesquisador (2008) a pesquisa descritiva é um estudo de status que é amplamente usado na educação e nas ciências comportamentais. O seu valor baseia-se na premissa de que os problemas podem ser resolvidos e as práticas melhoradas por meio da observação objetiva e minuciosa, da análise e da descrição. Muitas técnicas ou métodos de solução de problemas são incluídos na categoria de pesquisa descritiva.

Segundo Gil (1994), as pesquisas deste tipo têm como objetivo primordial a descrição das características de determinada população ou fenômeno ou o estabelecimento de relações entre as variáveis. São inúmeros os estudos que podem ser classificados sob este título e uma de suas características mais significativas é a utilização de técnicas padronizadas de coleta de dados.

Ainda segundo Gil (2010):

Entre as pesquisas descritivas, salienta-se aquelas que têm por objetivo estudar as características de um grupo: sua distribuição por idade, sexo,procedência, nível de escolaridade,estado de saúde física e mental etc. (GIL, 2010, p. 27,28)

Na pesquisa descritiva realiza-se o estudo, a análise, o registro e a interpretação dos fatos do mundo físico sem a interferência do pesquisador. 
A finalidade é observar, registrar e analisar os fenômenos ou sistemas técnicos, sem, contudo, entrar no mérito dos conteúdos.

Nesse tipo de pesquisa não pode haver interferência do pesquisador, que deverá apenas descobrir a frequência com que o fenômeno acontece ou como se estrutura e funciona um sistema, método, processo ou realidade operacional.

Trivinõs (2011,p. 110), discutindo sobre os estudos descritivos afirma :

A maioria dos estudos que se realizam no campo da educação é de natureza descritiva $\mathrm{O}$ foco essencial desses estudos reside no desejo de conhecer a comunidade, seus traços característicos, suas gentes, seus problemas,suas escolas,seus professores,sua educação,sua preparação para o trabalho,seus valores ,os problemas do analfabetismo,a desnutrição,as reformas curriculares, os métodos de ensino, o mercado ocupacional,os problemas do adolescente etc. (TRIVINÕS ,2011,p.112)

Trivinõs (2011), ainda ressalta que os estudos descritivos exigem do pesquisador uma série de informações sobre o que se deseja pesquisar, para que a pesquisa tenha um grau de validade científica necessita-se de uma precisa delimitação de técnicas, métodos, modelos e teorias que orientarão a coleta e interpretação dos dados. Trivinõs (2011), ainda ressalta que os estudos descritivos também podem ser chamados de estudos qualitativos.

Segundo Sampieri (2006), A abordagem qualitativa tem sido empregada em disciplinas humanísticas como a antropologia, a etnografia e a psicologia social. Conforme este autor enfoque qualitativo, dá profundidade aos dados, a dispersão, a riqueza interpretativa, a contextualização do ambiente, os detalhes e as experiências únicas. Também oferece um ponto de vista "recente, natural e holístico" dos fenômenos, assim como flexibilidade.

Laville e Dionne (1999), discorrendo sobre o tema, dizem, que a abordagem qualitativa permite apanhar uma parte da significação de um conteúdo através das freqüências e outros índices da importância relativa de seus elementos, daí o interesse de abordagens mais qualitativas que conservam a forma literal dos dados. O pesquisador decide prender-se as nuanças de sentido que existem entre as unidades, aos elos lógicos entre essas unidades ou entre as categorias que as reúnem, visto que a significação de um conteúdo reside largamente na especificidade de cada um de seus elementos e na das relates entre eles, especificidade que escapa amiúde ao domínio do mensurável.

A pesquisa de abordagem qualitativa proporciona um leque de métodos de investigação e coletas de dados, através de entrevistas, observações, documentos, registros, filmes. Sendo eleita aqui como forma de obtenção de dados a entrevista, por acredita ser através deste método a aquisição de resultados mais fidedignos com relação aos objetivos aqui desejados. 


\section{Instrumentos e Procedimentos de Coleta de Dados}

A entrevista semi-estruturada, busca alcançar uma maior profundidade nos dados coletados, bem como nos resultados obtidos, e o método do focusgroup, com base na análise dos dados obtidos na realização de entrevista, busca por via do confronto dessas respostas uma melhor compreensão do denominado estudo científico.

Conforme Laville e Dionne (1999), o recurso da entrevista semi-estruturada proporciona uma flexibilidade à coleta de dados, assim como uma maior abertura ao entrevistado, tornando dessa forma as respostas mais fidedignas, a qual se traduz através de uma série de perguntas que seguem o fio condutor que é a raiz da problemática, feitas verbalmente em uma ordem prevista, mas, na qual o entrevistador pode acrescentar perguntas de esclarecimento.

\section{O Pesquisador e a Entrevista}

Sempre em função da hipótese e das exigências de sua verificação, o pesquisador pode também reduzir o caráter estruturado da entrevista e torná-la menos rígida e menos constrangedora. Sobre essa ótica, torna-se importante observar a entrevista semi-estruturada, na qual se pode conservar a padronização das perguntas sem impor opções de respostas ao entrevistado. Dessa maneira, o pesquisador não interferirá e manterá a sua condição de neutralidade intacta e, principalmente pelo fato de que, deixando o entrevistado formular uma resposta pessoal, obtém uma ideia melhor do que este realmente pensa e se certifica, na mesma ocasião, de sua competência. Laville e Dionne (1999), expondo a cerca da entrevista semi-estruturada, afirmam que:

A Entrevista Semi-Estruturada Oferece Maior Amplitude Na Coleta Dos Dados, Bem Como Uma Maior Organização: Esta Não Estando Mais Irremediavelmente Presa A Um Documento Entregue A Cada Um Dos Interrogados. Por Essa Via, A Flexibilidade Possibilita Um Contato Mais Íntimo Entre O Entrevistador E O Entrevistado, Favorecendo Assim A Exploração Em Profundidade De Seus Saberes, Bem Como De Suas Representações, De Suas Crenças E Valores. (Laville E Dionne, 1999, P. 188 A 189)

Nos vale ainda enfatizar que segundo Laville e Dionne (1999) uma das primeiras tarefas do pesquisador consiste, pois, em efetuar um recorte dos conteúdos em elementos que deverão, em seguida, ser agrupados em torno de categorias. 


\section{A Importância do Resumo para o Processo de Pesquisa}

Resumo, segundo a Associação Brasileira de Normas Técnicas - NBR 6028/2003, trata da "apresentação concisa dos pontos relevantes de um documento". É uma apresentação sucinta e compacta, dos pontos mais importantes de um texto. Deve ser apresentado em uma sequiência corrente de frases e não caracterizando uma enumeração de tópicos.

\section{Objetivo}

Abreviar o tempo dos pesquisadores; difundir informações de tal modo que possa influenciar e estimular a consulta do texto completo.

\section{Como Fazer?}

O primeiro passo na elaboração de um resumo é definir qual o tipo será utilizado: indicativo ou informativo.

\section{Resumo Indicativo}

Sua função é indicar os elementos essenciais (tópicos e conteúdos) de um texto. Portanto, não dispensa a leitura do texto original para a compreensão do assunto. A norma da ABNT recomenda que o resumo tenha até 100 palavras se for de notas e comunicações breves. Se tratar de resumo de artigo, sua extensão será de até 250 palavras, nos casos de Relatórios, monografias, dissertações e teses pode agrupar entre 150 a 500 palavras.

\section{Resumo Informativo}

É uma apresentação concisa do documento de base, tem como finalidade a difusão de informações contidas em livros, artigos ou qualquer outro documento. Deve informar ao leitor as finalidades, metodologia, resultados e conclusões, de tal forma que possa, inclusive, dispensar a consulta ao original.

\section{Características}

- deve ser precedido da referência do documento;

- deve ser redigido em linguagem objetiva;

- deve apresentar seqüência de frases concisas afirmativas e não enumeração de tópicos;

- deve usar o verbo na voz ativa e na terceira pessoa do singular. 
Id on Line Revista Multidisciplinar e de Psicologia

id on Line Multidisciplinary and Psychology Journal

\section{Passos}

- utilizar as técnicas de sublinhado e/ou esquematização;

- descobrir o plano da obra a ser resumida;

- ater-se às idéias principais do texto e a sua articulação;

- responder, no resumo, a duas perguntas: De que trata o texto? O que o autor pretende demonstrar?

- redigir o resumo.

Resumos críticos são também denominados de resenhas ou recensões, não apresentam limite de palavras.

\section{Referências}

LAVILLE,Christian; Dionne, Jean.A construção do saber: manual de metodologia da pesquisa em ciências humanas.Porto Alegre : Artmed : BeloHorizonte: Editora UFMQ 1999. 339 p.

HEGENBERG, L.; ARAÚJO JÚNIOR, A.H. de; HEGENBERG, E.N. (Orgs). Métodos De Pesquisa: De Sócrates a Marx e Popper. São Paulo:Atlas,2012.

SAMPIERI, Roberto Hernández. Metodologia de pesquisa. 3. Ed. - São Paulo: McGraw-Hill, 2006. $624 \mathrm{p}$.

TRIVINOS,Augusto Nibaldo Silva. Introdução à pesquisa em ciências sociais: a pesquisa qualitativa em educação, $1^{\circ}$ edição ,São Paulo, Atlas. 2011

GIL, A. C. Métodos e técnicas de pesquisa social.4.ed São Paulo: Atlas, 1994.

. Como elaborar projetos de pesquisa. São Paulo: Atlas, 2010.

CERVO, A. L.; BERVIAN, P. A. Metodologia científica. São Paulo: Makron Books, 1996.

BARROS,Aidil de Jesus Paes de,Neide Aparecida de Souza Lehfeld..Projeto de Pesquisa: propostas metodológicas.Petrópolis,RJ:Vozes, 1990.

MARCONI, M. A.; LAKATOS, E. M. Metodologia científica. São Paulo: Atlas, 1991. Fundamentos de metodologia científica. São Paulo: Atlas, 2007.

MOREIRA,HERIVELTON.Metodologia da pesquisa para o professor pesquisador Luiz Gonzaga Caleffe.-2.ed.-Rio de Janeiro:Lamparina,2008. 
Id on Line Revista Multidisciplinar e de Psicologia

id on Line Multidisciplinary and Psychology Journal

RUIZ, J. A. Metodologia científica: guia para eficiência nos estudos. 6. ed. 2. São Paulo: Atlas, 2008. SAMPIERI, Roberto Hernández. Metodologia de pesquisa. 3. Ed. - São Paulo: McGraw-Hill, 2006. $624 \mathrm{p}$.

\section{Como citar este artigo (Formato ABNT):}

NUNES, Ginete C.; NASCIMENTO, Maria Cristina D.; LUZ, Maria Aparecida C.A. Pesquisa Científica: conceitos básicos. Id on Line Revista de Psicologia, Fevereiro de 2016, vol.10, n.29. p. 144-151. ISSN 1981-1179.

Recebido: 14/01/2016

Aceito:17/01/2016 